\title{
Enacting Ought: Ethics, Anti-Racism, and Interactional Possibilities
}

\author{
George N. Fourlas ${ }^{1,2} \cdot$ Elena Clare Cuffari ${ }^{2}$ \\ Accepted: 2 November 2021 / Published online: 1 January 2022 \\ (c) The Author(s) 2021
}

\begin{abstract}
Focusing on political and interpersonal conflict in the U.S., particularly racial conflict, but with an eye to similar conflicts throughout the world, we argue that the enactive approach to mind as life can be elaborated to provide an exigent framework for present social-political problems. An enactive approach fills problematic lacunae in the Western philosophical ethics project by offering radically refigured notions of responsibility and language. The dual enactive, participatory insight is that interactional responsibility is not singular and language is not an individual property or ability, something that someone simply and uniformly 'has' or 'controls'. These points have not been integrated into our self-understanding as moral actors, to everyone's detriment. We first advocate for adequate appreciation of Colombetti and Torrance's 2009 suggestion that participatory sense-making necessarily implies shared responsibility for interactional outcomes. We argue that the enactive approach presents open-ended cultivation of virtue as embodied, contextualized, and dynamic know-how and destabilizes an individualist metaphysics. Putting this framework to work, we turn to the interactional challenges of conversations that concern differences and that involve potentially oppositional parties, offering a reading of Claudia Rankine's Just Us. Finally, we make explicit Rankine's normative project of mindful navigation of multiple perspectives in an interaction. We abstract three interrelated spheres of participatory intervention: location, language, and labor. These also indicate routes for empirical investigation into complex perspective-taking in dynamic interactions.
\end{abstract}

Keywords Participation (or critical participation) $\cdot$ Linguistic bodies $\cdot$ Race $\cdot$ Social interaction $\cdot$ Knowhow $\cdot$ Decolonial theory $\cdot$ Perspective-taking

\section{Introduction}

Despite ceaselessly communicating in messages, media, and meetings, people fail to engage meaningfully with others, especially those outside of an immediate kin group or familiar relations. Here, we understand a meaningful (or, meaning-full) interaction to be distinct from solipsistic meanings that are maintained when actors engage with objectified notions of others rather than actual complex and possible others who are yet to be known. In this sense, meaningful interactions are a normative ideal that exceed individualistic solipsistic meanings. Like meaningful relations, solipsistic meaning can also vary in content, but it is generally marked by the reified preconceptions or judgments (i.e. objectifications) that are brought to interactions-the solipsistic actor

George N. Fourlas

gfourlas@hampshire.edu

Hampshire College, Amherst, USA

2 Franklin and Marshall College, Lancaster, USA treats the world as known, even if that knownness is haunted by Cartesian suspicion. In the U.S., struggles and complete misses of meaningful encounter are witnessed clearly in two overlapping arenas that we take to be reflective of global conflict more generally.

In one, a near-total epistemological and moral stand-off is occurring between political progressives (and some moderates) who simply cannot understand "Trump voters", while many Trump supporters express that they know too well the maddeningly foolish, naive, or 'elite' perspectives of the liberals against whom they react. Second, race relations, particularly Black-white relations, remain fatal for people of color in various contexts and locations-that is, the consistent brutalizing of Black Americans, including Black women, children, and trans persons, at the hands of the police. (Of course, the polarization and entrenchment of politics, as well as racism, extend far beyond the U.S., and though our focus is local the implications of this critique are global.) Yet even when white people are not murdering people of color, there is a basic tendency to resist or avoid interacting 
meaningfully - to only engage with the solipsistic objectified meaning - thereby deliberately or inadvertently denying racialized experience, whether as an outcome of guilt, anxiety, or material distance. A common ground can be named: in these cases, interactions are not only asymmetrically organized in terms of power, demanding a socio-historical analysis, but at the level of direct interpersonal encounter, participants oftentimes, even habitually, interact with objectifications, mythologies, and projections rather than actual, contradictory, idiosyncratic co-present others.

We aim to show that the enactive approach to mind as life can and ought to be developed to aid in addressing these real problems. Valuable collections of essays and conversations show the depth, nuance, and ubiquity of racism or at least misalignment between racialized bodies; yet, it is not always clear how we get from diagnosis to cure. ${ }^{1}$ Alfred Frankowski artfully captures this tradition of repetition as the Cassandra Complex: critical voices are not heard or headed, no matter how clearly or carefully they speak. ${ }^{2}$ If heard at all, the critiques register as accusatory, often leading to defensiveness and denial. Still, it is exigent that these critiques be heard and taken seriously. Our collective future is at stake and denial or blame are only making matters worse.

So, how do we get past what Jessica Benjamin calls a "doer/done-to" cycle, which blocks real relating ? ${ }^{3}$ The enactive approach helps meet a difficult challenge: maintaining the differences between and unique positioning of participants, while offering metaphysical support for shifting the moral weight off of individuals. In turn, investigating in detail the complex micro-contingencies of social interactions refines technical and ethical implications of participatory sense-making theory and its recent deployment in the theory of linguistic bodies. ${ }^{4}$

We maintain that two original and intersecting distinctions emerge in the approach that we present. Western ethics has yet to appreciate the enactive, participatory insight that interactional responsibility is not singular. Similarly, the insight that language is not an individual property or ability, something that someone simply and uniformly 'has' or 'controls', has not been integrated into our self-understanding as moral actors. Language and ethics, both fundamentally rethought in the enactive paradigm, intersect, in concrete and complex ways.

\footnotetext{
${ }^{1}$ Of course, the entire history of Critical Race theory/studies could be cited here, but popular discourse has been recently marked by several excellent volumes that the reader who is less steeped in the tradition will have likely, at least, heard of in passing. See, e.g., Wilkerson (2020) ; Cooper (2018); Kendi (2019); Oluo (2020, 2018).

${ }^{2}$ Frankowski (2012)

3 Benjamin (2018)

${ }^{4}$ De Jaegher and Di Paolo (2007); Di Paolo, Cuffari, and De Jaegher (2018).
}

Consider Humberto Maturana's etymological emphasis on seeing a conversation as a "turning around together" and his suggestion that communication requires first a matching, or physical compatibility, of organismic structural states. ${ }^{5}$ Martin Buber, in his famous phenomenological work on I-you relations, writes that "all actual life is encounter." Finally, Di Paolo, Cuffari, and De Jaegher define the watchword of enactive ethics to be "critical participation," meaning an enhancement of inclusive and reflexively engaged participation for all participants and on their own terms. ${ }^{7}$

As the opening problems indicate, there is a danger that in real life today, these pronouncements of authentic and transformative engagement might be lofty aspirations more than empirical descriptions of regular interactions. What is actually going on in interactions? What blocks critical participation? What enables it? What clues are there in Maturana's and Buber's suggestions? What advancements in social-political theory can steer a participatory sensemaking approach into grounded engagements, saving it from the fate of ideal theory that presupposes a coherent and consenting "We" where there is none and therefore, as Charles Mills rightly argues, excludes potential participants? ${ }^{8}$ The enactive approach must attend to myriad ways that participants end up conflicted to prevent as well as repair division, if the hope is to speak meaningfully of a larger collectivity.

The goal of an enactive ethics is not merely additive or working toward novel adjustments to an already established and functional value theory; rather, an enactive ethics aims to close the circle, to restore and reclaim value from speculative, abstract, and toothless discourses by attending to the complexity of interaction that makes it so difficult for people to do the right thing. The primary obstruction that we address is the divisiveness that was imposed and justified (by some of the most famous Euro-modern ethicists, as they either actively or passively benefited), which lingers as a festering wound, described by Aníbal Quijano and Sylvia Wynter as the coloniality of power. ${ }^{9}$ What Prato and Sidanius

\footnotetext{
5 Maturana (1978).

${ }^{6}$ Buber (1996, 62).

7 Ibid.

${ }^{8}$ Charles W Mills (1997); Pateman and Mills, (2007).

${ }^{9}$ Quijano (2007) ; Sylvia Wynter (2003). As just one example of Euromodern ethics justifying and largely benefiting from coloniality, consider John Stuart Mill's role in the East India Trading company coupled with his explicit racial excuses for paternalistic intervention. Also, we use the language of Euromodern to indicate two points: 1) that the tradition of thought that emerged along with the imagined European world is contingent or, as Chakrabarty (2000) puts it, provincial; 2) we also use this term because, as Lewis Gordon (2013) puts it, there have been other modern eras beyond that which is associated with western European colonial power, and there will be still more as European dominance erodes and transforms.
} 
call the 'arbitrary-set' and which we will discuss primarily as race is afforded through and enacted by an institutionally bolstered, hierarchically arranged organization that relies explicitly on naturalized objectified qualities such as, but not limited to, phenotype, and which operates socially and systemically. ${ }^{10}$ Race and racism stand in the way of meaningful and transformative engagements. While it is the case that the application of traditional ethical approaches might yield useful policy suggestions regarding racial injustice, any such attempt will consistently fail to be radical in the critical sense of the term-to get to the roots of the problem, to paraphrase Marx-by avoiding the ways that objectification is also reproduced socially and thus, at best, implicitly committing to the reification of race and racism rather than imagining a future where unjust hierarchies have been abolished through collective social action. An enactive ethics is the path to collective action, while holding significant promise for local and less strategically oriented problem-solving. At a range of scales, then, enactivism answers fundamental ethical questions any community may face: How can we be better, do good, or realize a more equitable world?

In the first section below, we review Colombetti and Torrance's foundational expression of an ethical approach derived from the enactive theory of social cognition, participatory sense-making. ${ }^{11}$ We respond to one of the few sustained discussions of this text, noting that it still stops short of appreciating the revolution of what Colombetti and Torrance suggest, which is that "full responsibility for a situation is no longer understood as lying exclusively with individuals. Rather, responsibility shifts and becomes more or less possible or potent, always within a particular intersubjective situation." ${ }^{12}$ We then argue that the enactive approach, insofar as it presents open-ended cultivation of virtue as embodied, contextualized, and dynamic knowhow, and insofar as it destabilizes an individualist metaphysics, is the missing piece that completes the field of ethical philosophical thinking. Putting this framework to work, we turn in the third section to the interactional challenges of conversations that concern differences and that involve potentially oppositional parties. Here we offer a reading of Claudia Rankine's Just Us. ${ }^{13}$ Rankine's examples in this text embody "the spirit of repair rather than blame" in turbulent interactions. ${ }^{14}$ In the final section, we make explicit Rankine's normative project of mindful navigation of multiple perspectives in an interaction. We abstract three interrelated spheres of participatory intervention: location, language, and

\footnotetext{
$\overline{10}$ Sidanius and Pratto (1999).

11 Colombetti and Torrance (2009).

12 De Jaegher (2018), “The Intersubjective Turn” p. 461.

13 Rankine (2020).

14 Ibid. Benjamin (2018), p. 19, fn 3.
}

labor. These also indicate routes for empirical investigation into complex perspective-taking in dynamic interactions.

\section{Reactive Attitudes or Interactive Entanglements?: The Question of Enactive Ethics}

An ethical orientation belongs essentially to the enactive approach to mind and language envisioned and practiced by Maturana, Varela, Thompson, Di Paolo, De Jaegher, and colleagues. It is not an add-on. Understanding enactive ethics is not a matter of applying theories of cognition to circumstances of moral weight. ${ }^{15}$ There are no morally neutral circumstances for complex living beings; accordingly, there is no cognitive activity divorced from the always already normative feats of existing as a living thing. "One of the biggest obstacles such an ethics must overcome is the widespread cultural assumption that moral reasoning is a totally unique form of judgement, unlike our ordinary processes of problem-solving in daily life." ${ }^{16}$ Hanne De Jaegher's corrective work similarly seeks to reorient scientific treatments of cognition around an overlooked achievement of human reasoning: loving each other. ${ }^{17}$

Colombetti and Torrance derive a new direction for ethics from the enactive theory of social cognition, participatory sense-making. ${ }^{18}$ Participatory sense-making offers a "description of social understanding in its most general form" 19 by identifying "the coordination of intentional activity in interaction, whereby individual sense-making processes are affected and new domains of social sense-making can be generated that were not available to each individual on her own." 20

For example, think of an adult playing "dinosaurs" with a toddler. They have dinosaur figures ranging in size and other affordances, and the adult and child may each sometimes be a dinosaur as well in the course of enlivening one of the figures. It is easy to imagine that how to play, what comes next, what essential elements distinguish this activity from another, etc. are all fairly fluid co-constructions that build off of each other and the toys, furniture, and levels of ingenuity

\footnotetext{
${ }^{15}$ For the purposes of this paper we use the language of morality and ethics interchangeably, though we recognize that a distinction is likely crucial for future work.

16 Johnson (2014), 28.

17 See also Backström et al. (2019) on philosophy of mind's inherently (but too often implicit) moral positioning and Maiese and Hanna (2019) on a deep connection between political philosophy and embodied philosophy of mind.

18 De Jaegher and Di Paolo 2007.

19 Di Paolo, Cuffari, and De Jaegher (2018), 73.

${ }^{20}$ De Jaegher and Di Paolo (2007), 497.
} 
and energy available in that moment. If the adult is doing it right, even probable asymmetries or competing cognitive demands do not overshadow the collaboration that characterizes the height of play. In this cheerful, idealized example, it is likely that true interactional autonomy may be both desirable and short-lived. Awkwardly endless conversations between coworkers who dislike each other, sexual advances made in an opportunistic setting, or an angry mob's haphazard decision-making each present a different story.

Participatory sense-making theory accords with the constructivist view basic to enactive thinking: actions change environments which in turn pose new pressures and opportunities for agents. A relationship of mutual constraint emerges when people interact such that "interactions form and transform individuals and their intentions, just as individuals form and transform interactions." ${ }^{21}$ The central idea of participatory sense-making "...does specify... something that goes beyond the simple conjoining of sense-making and a social situation... it is sense-making performed socially, enacted as a shared practice." 22 Meaning in a social setting is an achievement complexly co-assembled by participants and the emergent interaction dynamic. This whole host of autonomies struggles through tensions to an outcome that cannot be reduced to a single agency (although post-hoc contributions may be identified and attributed in some cases).

Colombetti and Torrance, on our reading, clearly state that participatory sense-making shifts moral responsibility away from an individualistic framework. ${ }^{23}$ As we discuss, this does not imply an absence of consequences nor a lack of responsibility or accountability at the level of individuals involved (no hard-determinism reading is necessary). What the theory of participatory sense-making as a theory of social cognition does imply is that no single participant is in total, isolated control (not over her own behavior nor the other's nor their intercourse) in an interactional encounter, and what it does suggest, and provoke, is an inquiry into moral agency. ${ }^{24}$ Colombetti and Torrance initiated this inquiry. ${ }^{25}$

We find that the central insight of Colombetti and Torrance's paper gets misplaced in critical rejoinders. For

\footnotetext{
21 De Jaegher (2018), 455.

22 Di Paolo, Cuffari, and De Jaegher (2018), 74.

23 Colombetti and Torrance (2009).

${ }^{24}$ Di Paolo, Cuffari, and De Jaegher (2018), 314.

${ }^{25}$ See Torrance and Froese (2011). Importantly, researchers have advanced the idea of an enactive ethics by noting its convergences with other marginalized branches of philosophical ethics including care ethics (Urban 2014; (2015) and Levinas's other-first ethical phenomenology (Métais and Villalobos 2020; Dierckxsens 2020). Others still call for a clearer articulation of moral normativity in the enactive approach (Barrett, García-Valdecasas, \& Sánchez-Cañizares (2018); Hutchinson (2019).
}

example, Jana Van Grunsven attempts an immanent critique of Colombetti and Torrance's argument, concluding that in advocating avoidance of "making judgments of individual responsibility" they in fact fail to prioritize secondpersonal engagement. ${ }^{26}$ This reasoning rests on a reading of Strawson's theory of reactive attitudes as saying that it is an unchanging fact of human nature that we get caught up in evaluative participant stances. Strawson identifies a fascinating phenomenon that is rich in implication for social cognition and for moral psychology: part of participating in an interaction is undergoing affective reactions to others, and these reactions are evaluative. For example, you receive poor service in a restaurant setting, and experience resentment at being overlooked or disrespected. "According to Strawson, reacting to this situation with resentment just is a way of targeting the waiter as someone who has intentionally violated the normative expectations for interpersonal regard that we have in our ongoing everyday engagements with one another; it is a pre-theoretical way of identifying the waiter as a moral agent whose action is appropriately susceptible to judgments of blame." ${ }^{27}$ Such reactions can be mitigated by injury-excusing or agency-excusing conditions; one steps back from the interactional setting and accompanying reactions, is no longer a participant, and instead takes an objective, third-personal stance in order to consider mitigating factors and revise one's initial judgment. Perhaps the server had just been chewed out by her boss or has a migraine but can't afford to stay home from work. One overrides the in-the-moment reaction of resentment by taking in new information or by assuming the stance of someone less partial, less caught up. But what might really be happening here is a realization of the solipsism of the participant attitude; by considering others, one moves away from the solipsistic meaning that initially overdetermined and thus undermined the situation, making other relation modes possible. Van Grunsven surmises, "Note how, much like enactivists who challenge the commonplace that social cognition is first and foremost grounded in a third-person stance of observation, explanation and prediction, Strawson maintains that a third-person attitude towards other persons indicates a modification of, and thus presupposes, the more pervasive orientation we have toward one another when we occupy a participant attitude." 28

Indeed, this is a point of potential contact between Strawson and the enactive approach of participatory sense-making. But identifying caught-up-in-the-moment judgmental reactions is not the same thing as endorsing them, nor must it require naturalizing them-that is, the content of our

\footnotetext{
$\overline{26}$ van Grunsven (2018).

27 Ibid. 150.

28 Ibid. 152.
} 
reactive attitudes can change, in the moment and over time as a result of training, even if the fact of reactive attitudes is "human". Furthermore, it is not prima facie evident that the temporal logic of reactivity maps correctly the dynamic, intercorporeal, and entangled landscape of participatory sense-making. Certainly, reactive attitudes are normative second-personal phenomena, as forefronted in Bennett Helm's definition of them as "reactions to the standing others have as members of a particular community of respect." 29 As such reactive attitudes entail interpersonal commitment or "pressure" that takes the relational forms of an "address" and "call." ${ }^{30}$ Moreover, these "commitments to import" are not necessarily "passive responses to our circumstances" but admit of more active contributions and so range from emotional responses to evaluative judgments. ${ }^{31}$

Yet, as in Colombetti and Torrance's intervention, the project at hand is tracking the implications that participatory sense-making, in claiming that social interaction can constitute social cognition, holds for ethics. This requires reckoning with the idea that in between community and individual, an interactional milieu intervenes that is irreducible to either. Traditional philosophical deployment of ideas like commitment, emotion, judgment, and attitude, even while conceptually implying relationships with others, may reinforce the individualist foundation that is meant to be broken up and replaced by something transpersonal, namely, the primordial tension of participatory sense-making and its fundamental displacement of the unified and singular self as the center of sense-making activity. ${ }^{32}$ Only then can the possibilities (including possible shortcomings) of an enactive ethics appear.

\section{Closing The Circle: The Necessity of Enactive Ethics}

Perhaps one of the most significant if not widely discussed articulations of ethics from an enactive perspective is found in Francisco Varela's Ethical Know-How. ${ }^{33}$ Varela distinguishes between ethics as an abstract and rational project, which he frames as know-what, and ethics as a spontaneous coping, or know-how. The Euromodern tradition of philosophical ethics largely concentrates on ethics as a know-what, an abstract rule-based system that judges, as if value and meaning exist beyond or outside of lived experience. Ethics as know-what is to be imposed or recognized

\footnotetext{
${ }^{29}$ Helm (2013). 199.

30 Ibid, 209

31 Ibid, 212-214.

32 Cuffari, Di Paolo, and De Jaegher (2015).

33 Varela (1999).
}

through proper reflection, and generally seems to require an obedience or submission to a god-like, monarchical, or bureaucratic figure. Importantly, one's ethical failures are individual and one is held accountable as a rational isolate.

One can juxtapose this top-down rule-based model with praxis, or the actual uptake of ethical values in interaction. Indeed, anyone who teaches ethics will, at some point, be challenged to account for how we can actually be ethical, be better people, in practice and not just in an armchair. From a traditional perspective it may appear easy to pronounce what is good and bad, but successfully enacting whatever it is we ought to in our daily activities is complicated. Recurring classroom demands for practical ethics point to a gap in the tradition. The enactive approach completes this philosophical project by both (1) bringing attention to how meaning and value emerge through relationships, and (2) by offering normative ideals to support interactions towards a greater reciprocity for involved parties, specifically the idealization of co-creation or co-operation in meaning making activities. These two characteristics are intertwined because attentiveness to participatory action (1) is itself a normative demand through which further ideals (2) can be illuminated. Enacting a collectively achieved "ought" therefore requires, first and foremost, an eco-social interpretive stance, what Martin Buber calls an I-You relation, or what Bantu philosophy refers to as an mbuntu/ubuntu relationality that emphasizes 'I am because we are.' ${ }^{34}$

Regarding the enactive paradigm shift, Varela turns our attention to know-how, or the local level coordination that is involved in acting with/through a relational world. As Varela puts it, "our lived world is so ready-at-hand that we have no deliberateness about what it is and how we inhabit it." ${ }^{35}$ Of course, since rational or top-down ethics is the prevailing way of thinking about value, then the participant, assuming they are pseudo-agential or already socialized through an overarching set of cultural norms, carries with them a certain predisposition or a background moral framework that might be offended or pleased in interaction. Reactive attitudes are what they are, at least partly, because of the community norms through which we have already been conditioned. Nevertheless, every situation takes on a life of its own such that who we are, how we engage, and what emerges from within any given context is beyond our complete control. Indeed, Varela frames the contingent experience as a microworld wherein participants take on a micro-identity such that our sense of self, "who we are," Varela says, "at any moment cannot be divorced from what other things and who other people are to us." ${ }^{36} \mathrm{We}$ are not monads, and thus our

\footnotetext{
$\overline{34}$ Ibid. Buber; On Ubuntu, see e.g., Tempels (1969).

35 Varela (1999).

36 Ibid. p. 10
} 
capacity to do the right thing is informed by the conditions through which we engage. Importantly, who we are shifts across experience: For the enactivist, there is no fixed or rigid self that stands outside of relationality. As Enrique Dussel puts it, "A person is a person only when he or she is 'before,' somehow in confrontation with, another person or persons. Solitary and alone in the presence of impersonal nature, one ceases in a certain sense to be a person." 37

In the Euromodern tradition of ethical know-what, the model of accountability is one of praise and blame, which are highly individualistic forms of behavioral critique. The western world maintains what Jessica Benjamin refers to as a "doer/done-to" modality, wherein blame is attributed to an individual actor, an offender, who stands in an asymmetrical relation to a victim. ${ }^{38}$ An asymmetrical approach to praise and blame is grounded in a pervasively asymmetrical political system. ${ }^{39}$ Our interactions are oversimplified as one-to-one transactions and in some cases it is obvious why this perspective is maintained: it is a colonial ideology that supports asymmetrical power relations. Negotiating with individuals, or 'free agents,' rather than unions, for example, allows for the consolidation and maintenance of corporate power over time. In western culture, power through domination implicitly serves as a moral norm, acting as a benchmark for success (or failure) (e.g., greed is good). Despite the bald immorality of these power asymmetries, the ideological narrative suggests that some sort of ethical sensitivity remains, such that we are expected to inherently know when power has been abused and when a victim is properly a victim. But of course, under these oppositional circumstances the recognition of a victim as a victim, especially at the institutional level, is primarily instrumental. Indeed, the law is supposed to regulate how far is too far but operates after the fact, leaving a trail of victims in its place. Consider the obvious paradoxes and double-binds of rape culture and toxic masculinity, in which young men are raised at once to be "gentlemen" and "beasts." 40 False claims to ethical sensitivities at the institutional level yield profoundly unequal results: \#notallmen commit assault but \#yesallwomen live in fear of it. ${ }^{41}$ In the United States court system, to consider another example, the victim is explicitly treated as a means to prosecuting the offender and with little regard for the trauma experienced by the participant in the victim role, neither during the judicial proceedings nor after the fact.

\footnotetext{
37 Dussel (1988), 9.

38 Ibid. (2018).

39 This is similar to the "mindshaping" argument in Maiese and Hanna (2019).

40 Bordo (1999).

${ }^{41}$ Solnit (2015).
}

The shift to an enactivist perspective is an improvement because it involves the recognition of a more complicated notion of agency that extends beyond binary and oppositional actors. After all, who is harmed by violence when it ravages our social environments? Obviously there is an immediate physical harm, but the reverberations of that damage extend well beyond the singular body. Anyone who has ever lost a loved one to violence always carries that trauma, the incalculable and permanent impact of love lost. Entire worlds are upended by violence, not just the lives of one or two individuals. And, insofar as the role of the offender is also occupied by a complex participant, we might ask what world did that person come from? Who was left behind by their actions? Every person who is sentenced to a life in prison is also a child, a sibling, a cousin, and possibly a parent, now socially dead and thus another open wound that compounds the lingering dynamism of coloniality. The absence of incarceration is carried by those who remain: the child whose parent is trapped in prison also suffers, unjustly, and with little recognition of the debt they too pay. Retributive accountability leaves the whole world blind and our needs unsatisfied. In other words, as we are all connected, what becomes of us when we separate out and thus punish the individual? ${ }^{42}$

The social world within which most people operate is highly divided against itself, and this horizontal division allows for the maintenance of vertical asymmetries to persist (i.e. the coloniality of power). A focus on local conflicts, disruptions, and failures can be understood as akin to preventative care when seen as connected to larger social-political problems. We focus in the next section on the phenomenon of microaggressions as a pertinent example of daily conflict that is exacerbated by an individualist paradigm. Di Paolo, Cuffari, and De Jaegher offer an initial enactive analysis of

\footnotetext{
${ }^{42}$ Examples of direct and immediate violence of the kind that lead to judicial interventions are overemphasized in Euro-modern ethical discussions that rely on western intuitions to verify and reinforce slight variations of the rational paradigm. Rarely is the average person in the position of deciding whether or not a runaway train should kill one person or six, or, in the more relevant case of macro-political leaders, whether a drone strike should kill one civilian or six. On this later modification of the trolly problem, a small portion of the human population ends up being responsible for making the sort of top-down decisions that require a utilitarian or some rigid deontological framework, determining the conditions through which labor will be exploited or how many people will starve in the name of capitalist 'progress.' Far more tangible if not less complicated to the overwhelming majority of the world population whose lives are burdened by the rational decision making of a select few are the various ways that harm occurs and that interactions fail to realize a shared meaning in our everyday encounters. Indeed, the possibility of criminalized violence is in some ways an extension of these more local failures combined with top-down constraints compounding over time, which is one way of understanding Jeffrey Reiman's claim that The Rich Get Richer and the Poor Get Prison (Reiman 2010).
} 
microaggressions in terms of harms to linguistic bodies, i.e., subjects whose dimensions of bodily existence interpenetrate in living, emerging identities woven together by utterances. They write, "the acts that constitute linguistic bodies are themselves previously received acts of others both near and far, known and unknown. ... for linguistic bodies tensions between past and present, and self and community, amplify and distort this basic ongoing challenge. Such complexity manifests in a variety of ways in interpersonal exchanges, and sustains an excitable field-in some cases one is tempted to say a minefield —of potential harms." ${ }^{43}$

Building on this, understanding what is happening in microaggressive interactions also requires understanding how the history of systemic racism in the U.S. is lived, unevenly, in the bodies of its residents. ${ }^{44}$ Microaggressions and interactional failures that may beset even well-intentioned conversations serve as important test cases for an ethics rooted in participatory sense-making. Not only do we have to bring in the constraining and constituting historical and present-day realities of (racist) institutions, but also the asymmetries and complex interactional histories, both personal and shared, for participants. ${ }^{45}$

Note that we do not interpret a shift to an interactionoriented ethical point of view as simply shifting blame to both parties or as sharing blame, as if to say, for example, that folks of color are also responsible for the slights, insults, harms, and perpetual disempowerments that occur during conversations, meetings, or other institutional interactions. The goal is not, we think, to spread blame further. ${ }^{46}$ As Claudia Rankine and Brittney Cooper have shown, people of color are more likely to be keenly skilled at reading, holding space for, and anticipating the emotions of whites. Audre Lorde makes a similar claim, suggesting that those who exist and operate from subjugated positions too often carry the

\footnotetext{
$\overline{43}$ Ibid. 2018, 314-315.

44 This is philosopher Megan Burke's question in When Time Warps: The Lived Experience of Gender, Race, and Sexual Violence (2019). Burke analyzes the myth of the Black rapist as a fear lived by white women in their concrete, conditioned comportments in going out at night, getting into a taxi or elevator, etc. The myth of the Black male rapist simultaneously organizes the Black male body, and similarly in fear, now of the reactive danger of white fear and what Brittney Cooper names "white-girl tears" (Ibid. 2018).

${ }^{45}$ See also Steiner and Stewart (2009); Torrance and Froese (2011).

46 Note that Colombetti and Torrance instead introduce an increase in humility: "For if action takes shape more in the melting pot of collective extemporisation than as an agregation of individual moves in an interactional chess game, then it appears that we have to be more humble in our ethical appraisals-for two reasons. First, we may have to accept a liberal share of co-ownership of what we see as the less attractive features of how others act in a given situation. And second, and conversely, we may have to concede to others in the situation a liberal share of co-ownership of those aspects of our own acts that seemed to put us in a personally flattering light." $(2009,523)$.
}

ethical burden of care and awareness that we normatively expect all persons to shoulder:

Traditionally, in american society, it is the members of oppressed, objectified groups who are expected to stretch out and bridge the gap between the actualities of our lives and the consciousness of our oppressor. For in order to survive, those of us for whom oppression is as american as apple pie have always had to be watchers, to become familiar with the language and manners of the oppressor, even sometimes adopting them for some illusion of protection. Whenever the need for some pretense of communication arises, those who profit from our oppression call upon us to share our knowledge with them. In other words, it is the responsibility of the oppressed to teach the oppressors their mistakes. ${ }^{47}$

And yet, despite, indeed in some ways as a result of, this uncloseable sensitivity that Lorde and Rankine so intricately capture, the insults and injuries persist. In other words, it is as though one side of the interaction is not fully there- the side of privileged whiteness, which can be characterized as a failure to fully engage the human capacity to be present, as a persistent systemic avoidance of the necessary condition of vulnerability in all meaning-making, or a stubborn maintaining of solipsistic meanings. The goal, then, is to bring systemic asymmetries into the theory along with the reality that vulnerability in interactions can be and regularly is ignored. Cases like microaggressions make it all the more urgent that people learn to notice, detach from, and revise their reactive attitudes- these absolutely cannot be naturalized or held up as the 'real' or 'normal' way of being in interpersonal interactions.

\section{Anti-racism in the air: training in enactive ethics}

Much of the debate around microaggressions focuses on the extent to which persons intentionally or unintentionally enact racist stereotypes, expectations, and norms in their interactions. Though the conversation about intentionality is important, we believe that the problem can be fruitfully redirected through an enactivist framework that challenges us to rethink agency, responsibility, and our capacity to change. Here, we juxtapose interactional collapse with more successful interaction dynamics in order to flesh out the conditions of cooperative meaning making.

To begin, we want to attend here to the way that practices of praise and blame, which are rooted in a retributive

\footnotetext{
$\overline{47}$ Lorde (2007), 114.
} 
or punitive ethos, ultimately shut down the transformative process and thus foreclose the possibility of an anti-racist future. The collapse of interaction dynamics is clearly witnessed in some of the ways that a culture of 'calling out' has emerged in response to deeply rooted social-systemic injustices throughout the United States. Those who work in the academy often witness this sort of punitive call-out happening between students. In the best cases, the anti-racist call-out is understandably righteous, the speaking actor feels a moral responsibility to call it when they see it, ideally creating a moment wherein the racist is expected to reflect on their racism and change. The assumption underlying the best form of call-out culture reflects an incomplete version of what John Braithwaite calls "reintegrative shaming," which he describes as follows: "Reintegrative shaming communicates disapproval within a continuum of respect for the offender; the offender is treated as a good person who has done a bad deed." ${ }^{48}$ The emphasis on shaming behavior is key, however, because most call-out events fail to separate the 'sin' from the 'sinner' and thus the shamed actor is, following Braithewaite's critique, stigmatized. Stigmatization has a tendency to reinforce or increase shameful behavior, as Braithewaite puts it,

Stigmatization is disintegrative shaming in which no effort is made to reconcile the offender with the community. The offender is outcast, her deviance is allowed to become a master status, degradation ceremonies are not followed by ceremonies to decertify deviance. $^{49}$

Of course, it is understandable why one might struggle to separate racism from the racist, especially when the mainstream assumption about human agency is that individuals are fixed over time-we have something of a soul, but with the death of god we secularize the notion as a 'mind' that serves the same purpose of cutting us off from ourselvesand also deliberate from a position of radical freedom. A fully worked-out enactive ethics would challenge these fundamental assumptions while maintaining that racism is morally wrong, but the conditions of moral assessment and the outcomes that follow from that assessment are radically divergent, precisely because of the framework that guides those processes. Put simply, racism is descriptively wrong for all of the reasons spelled out by the range of critics who have collectively and rigorously debunked racial science, while it remains morally wrong, on our enactive ethical view, because it works to foreclose, or actively annihilate,

\footnotetext{
48 Braithwaite (2000), 1.

49 Braithwaite (1989), 101
}

possibility and specifically the possibility of meaningful interaction amongst linguistic bodies. ${ }^{50}$

In contrast to these failed interactions, we analyze three examples from Claudia Rankine's Just Us. ${ }^{51}$ Throughout the chapter, "liminal spaces i," Rankine recounts various interactions she engages in while literally and figuratively between spaces, in airports and in-flight, that can be more or less understood as microaggressions insofar as the experiences are not direct assaults on her person, but repetitive slights that are known and often unaddressed because of the "silencing mechanisms of manners." ${ }^{52}$ The microaggressions recounted by Rankine range from being cut off while waiting in a line for first-class ticket holders-an experience that is accompanied by a screenshot of Traci Blackmon's facebook post from May 2019 recounting a similar experience-to a drawn-out but incomplete conversation with a white man about privilege. ${ }^{53}$ Part of the residual strain that is emphasized throughout this chapter comes from Rankine's own struggle to respond to microaggressions, to overcome the tendency to hold these slights rather than address them when they emerge. The struggle to fully address interactional slights of the microaggressive variety is complicated by at least two variables: 1) the temporality of the interaction is often quick and thus makes it easier for the privileged to feign ignorance or forget; but, 2) when extended time is available, the second and more important variable is the receptiveness of the other participant and, specifically, the capacity and willingness to be wrong.

Consider the first example. When cut off in line, Rankine says "Excuse me...I am in this line" to which a white man replies: "You never know who they're letting into first class these days. ${ }^{~} 54$ The response itself creates an opening that can be broadly interpreted, and Rankine proceeds to unpack possible meanings. Immediately after describing the interaction, she connects the experience to similar moments, including the account offered by Blackmon, and then includes her therapist's comments. It should not be shocking, yet for some (white) readers it is perhaps rare to have the opportunity to see and know, that this sort of interaction is haunting, to the point that it must be exorcised through writing, therapy, comparison with others-to affirm, not alone, and confirm, not crazy. Even though Rankine remained in-flight with the man, who, on an individualistic model might be called the

\footnotetext{
${ }^{50}$ For more on this critique of call-out culture and anti-racist practice, see the forthcoming Anti-Colonial Solidarity: Race, Reconciliation, and MENA Liberation by G. N. Fourlas.

51 Ibid. Rankine (2020).

52 The silencing mechanism of manners coupled with the real material concern of being 'unruly' and thus removed from the flight or murdered.

53 Ibid. 22.

54 Ibid. 23.
} 
offender, the interaction collapsed into a stalemate of cryptic glances whenever the man got up to access the overhead compartment. ${ }^{55}$

Rankine's guesses at what her presence in first class ultimately means to the man must be incomplete, because the interpretation cannot be verified without the others' participation. The relation is left in tension. Both parties project expectations based on their social-historical backgrounds and experiences, assuming to know the other the same way one knows a tree without its specificity. In addition to meeting the necessity of dealing with differential historical embodiment, a full analysis must note that a microaggression does not simply reduce the receiver to a physical characteristic (to one dimension of embodiment) but to a mythological existence linked to this physical characteristic or identity projection, one that is well known to both parties even if it is false. ${ }^{56}$

In instances like this first example, the endless possibilities of the other (perhaps the white man felt the discomfort of what had happened but lacked the courage to apologize, perhaps he really did hate Rankine because of her perceived race, perhaps he thought she looked familiar and wanted to try again, to reconnect with a fleeting possibility that disappeared a long time ago) are limited to unverified and objectifying projections. Avoiding the tension guarantees its haunting impact. Rankine could have responded differently in the initial encounter, putting niceties aside and calling-out the white man, for all to see, which would have shifted the weight of the event more fully onto the other but at the risk of Rankine herself being seen as 'angry' and 'unruly,' while still completely shutting down the interaction. This resonates with Benjamin's account in which doer and done-to are mutually supporting, all-too-familiar, egging-on roles, as when she observes, "ironically, each person may feel coerced by the other, as if pushed into their assigned role, neither in control. Where then is goodness? Where is badness?"57 Here, participants were not able to transcend undesired, interactionally-assigned roles.

In another case wherein Rankine experiences microaggression, she is seated next to a white man with whom she ends up conversing. The man asks what she does for a living and Rankine says that she teaches at Yale. "He told me his son wanted to go there but hadn't been accepted during the early-application process. 'It's tough when you can't play the diversity card,' he added." 58 The time after this statement and the next is unclear, but Rankine's thoughts are captured as she works through how to respond. Before she

\footnotetext{
55 Ibid. 25.

56 See Fanon 2017, specifically chapter 6 .

57 Ibid. Benjamin (2018), 5.

58 Ibid. Rankine (2020), 41.
}

has a chance to say anything, however, the man continues: “'The Asians are flooding the Ivy Leagues'...perhaps the clarification was intended to make it clear that he wasn't speaking right now about his fantasies regarding Black people and affirmative action. He had remembered something. He had recalled who was sitting next to him." ${ }^{59}$ Unlike the previous example, however, Rankine pushes this conversation: "Then I did it. I asked. 'I've been thinking about white male privilege, and I wonder if you think about yours or your son's?' It almost seemed to be a non sequitur, but he rolled with it. 'Not me,' he said. 'I've worked hard for everything I have." ${ }^{60}$ Rankine continues to push the conversation, probing with great care in the hopes of not shutting down the interaction,

"I wanted to keep talking with this man...I didn't want our different historical positioning to drown our already shipwrecked chat. I wanted to learn something that surprised me about this stranger, something I couldn't have known beforehand."

The meaning of the man's foot-in-mouth performance is brought out entirely, for it turns out that the man's son did not get into Yale, but his son's best friend, who is objectified as Asian, was accepted and the man manifested his resentment in racist speech. Rankine works to stay engaged with this man, to understand him and how he feels about his son's future, in a demonstration of intentional perspective-taking: "Know what it is to parent. Know what it is to love. Know what it is to be white. Know what it is to expect what white people could have whether or not luck or economics allow you to have it. Know what it is to resent." ${ }^{2}$ It is unclear, however, if the man was moved at all to try and understand Rankine's perspective. Indeed, the outright denial that he might benefit from his positionality, expressed through his juvenile 'not me, I've worked hard for everything I have,' exemplifies the closure and solipsism that prevented the normative transformation we are defending. Still, while imperfect, this is a more satisfying exchange that begins with a micro-aggression, which the participant incompletely repairs, and eventually moves through a meaning-making activity, mostly because of Rankine's intentionality, appreciation of nuance, and caution, that may or may not have transformed both parties.

Rankine presents a third interactional experience, which we do not classify as a microaggression. Although the performance of the other participant is a possible slight, when Rankine problematizes the participant's position the man

\footnotetext{
$\overline{59 \text { Ibid. 41-42. }}$.

${ }^{60}$ Ibid. 43.

61 Ibid. 45.

62 Ibid. 47.
} 
recognizes his failure and accounts for it in the moment. The overarching feel of this interaction, Rankine emphasizes, was much lighter from the initial contact: "I was, metaphorically, happily outdoors with this man, who was open and curious with a sense of humor." ${ }^{63}$ Eventually the conversation turns when the man begins describing his work, wherein he notes that "he had been working on diversity inside his company... 'We still have a long we to go,' he said. Then he repeated himself-'we still have a long way to go'-adding, 'I don't see color.", ${ }^{64}$ Rankine describes this moment as if the phrase "pulled an emergency brake," a disruption in an otherwise friendly interaction that elicited a flurry of possible responses to the failed performance, eventually arriving at "if you can't see race, you can't see racism." ${ }^{65}$ Rather than react defensively or double down, trying to argue for an obviously wrong position, the man admits his error and asks if he had failed elsewhere in the conversation, to which Rankine says no.

What Rankine does in this exchange as in the previous one is similar to what George Yancy attempts in his famous "Dear White America": she is offering the man a gift. ${ }^{66}$ Unlike the multitude who reacted to Yancy with visceral hate, the man beside her accepts the gift. Acceptance transports him alongside Rankine on the transformative journey that we read the text to be chronicling.

Mutual vulnerability is the key in this exchange. Rankine openly observes her interlocutor's failure; he recognizes it as such; she allows it to be what it is without shutting down the interaction. Perceiving others as holding out various affordances for interpersonal encounter is no simple feat. It is likely that one's perceiving will be filtered by one's own habits, needs, and wants. Moreover, responding to what one senses in the other must not morph into overdetermining the other or the interaction; the descriptive and normative imperative of social interaction requires fostering the autonomy of each. Acting on perceived interactional affordances entails recognizing (or failing to recognize) another's agency. ${ }^{67}$ Moreover, the affordances perceived in the human social world, however direct they may be, are rooted in convention and can be wrong. ${ }^{68}$ Perceiving affordances can be wrong in the sense of inaccurate: I may perceive the presence of beer but find out the can is filled with water (to borrow Chemero's example), but also wrong in the sense of unethical: I perceive a doting older relative eager for company as an opportunity to secure a future inheritance. In this third example from Rankine's text, we witness the participants recognizing and co-regulating the latent harm of the exchange, laying down a better path.

We read these cases as real, particular moments that are not in themselves replicable. Contrary to the deluge of strongly normative PSA-style advice on Instagram and Twitter, there is no script for avoiding interactional harm. Furthermore, Rankine is not just any participant. She is a writer and professor with a professional-creative mission as well as a robust critical framework and can engage as such. She is a Black woman, of a certain age, moving in certain spaces. The differences these differences make in the interactions she recounts show us how important it is to keep space for the singularities of and asymmetries between participants in interactions.

Does this mean we are disagreeing now with Colombetti \& Torrance, falling back into an individualistic framework? No. It is precisely Rankine's release of a punitive, blaming ethos that enables her to be present, intentional, and open in these interactions. She presents these three examples in chronological sequence, performatively demonstrating some of what we describe as intentional training undertaken in an effort to be skilled like this in spontaneous interactions, to have the know-how needed to sustain anti-racist growth in interactions. We think these cases concretize what Di Paolo et al. mean when they say "Entrenched perspectives will never really be changed if we [as a linguistic community] do not learn to speak differently." ${ }^{69}$ Speaking differently doesn't mean everyone in the community magically learns to say the "right" thing in every instance - and this cannot be a sufficient moral norm anyway. As we see with the failure of political correctness, a pick-up 'artist' (i.e. predator) can easily deploy feminist vocabulary to decidedly anti-feminist, questionably consensual ends. Speaking differently means being the kind of participant who strengthens community norms by practicing them, not manipulating them for selfish interests, and helping one's co-participants to practice them for the good of all, interaction by interaction, with mercy and patience. These norms value working to keep interactions open, steering them towards reciprocity and on-going possibility to participate, rather than closing into assignments of praise and blame. ${ }^{70}$

\footnotetext{
$\overline{69}$ Ibid. (2018), 310.

70 This is in line with what Loretta Ross (2019) describes as "calling in" rather than participating in call-out or cancel culture.
} 


\section{I, You, and all of us: an Enactive Ethics of Interacting}

Concretely, we see in the nuances of Rankine's introspective intentionality and in the much more widespread and typical blow-ups of microaggressive interactions that being ethical in interactions requires training in discomfort and finding ways to co-adjust our spontaneous coping. We also observe that our linguistic behavior is utterly intertwined with (emerging from and continuously redrawing) interactional situations and the lived experiences of the bodies participating. Even with awareness and training, of course, and precisely because this is a question of ethical practice, situations will sometimes fail, leading to outcomes that range from breakdown to brutality. Acknowledging the frequency of failure and the attendant space needed for humility, charity, or even forgiveness, it is clear that balance is badly needed in the U.S. context when it comes to the labor of communing. Public interactions cannot continue to be organized around one-sided expectations that people of color, marginalized people, or various activists will keep vulnerable and open as a counterbalance to fragility, myopia, negligence, or defensiveness in interactions. Well-intending U.S. communities must progress beyond cycles of book clubs, shootings, and more book clubs. ${ }^{71}$ How do we bring about broader transformation to realize this shift in community norms?

While we could not presume to answer this in any complete or final way, we abstract a few critical observations, each of them suggesting normative practical interventions for individuals and communities in the spirit of furthering critical participation, as well as avenues for empirical research to investigate our intuitions. In learning how to interact in ways that truly accommodate and stay open to difference, location, language, and labor mark three spheres of plausibly powerful intervention.

\subsection{Location}

Drawing on conflict resolution theorist John Paul Lederach, we maintain that reconciliation is a place. ${ }^{72}$ Let's attend to the details in Rankine's accounts. She is stuck with these white men in airports and airplanes. One does not choose one's companions when flying, though of course one is involved in co-navigating how (much) to engage with other travelers. People are not simply thrown together at a gate or in a row on the plane: they are confined in a disarmed public location that is presumably physically safe. Enough

\footnotetext{
71 Johnson (2020)

${ }^{72}$ Lederach (1997), 27. See also, e.g. (Fourlas 2015a, ba, b; 2015a, $\mathrm{ba}, \mathrm{b})$, where the demand for a neo-agora or communal reconciliation place is more forcefully articulated.
}

constraints are in place that, again presumably, the most one has to navigate is civil discourse. In airports, all bodies are potentially suspect, subject to search and seizure, and in a state of institutional inferiority insofar as border crossing is arranged as an abject plea to authority. While we are not suggesting that everyone should head over to an airport to better do anti-racist work, several important points are disclosed in attending to the situations in which Rankine works to interact ethically.

Firstly, strong norms are in play. There are ways one has to conduct oneself to make a flight successfully and be in public with strangers correctly. Secondly, there is relative safety and neutrality. The title of Rankine's chapter is "liminal spaces"- everyone is no one, everyone is in between and on the move, in transition, and maybe open to transformation. Thirdly, there is not much to do. Phones are off, business as usual is paused or at least slowed. Finally, there is often a diversity of humans present. More features may be observed. The point is, there are better and worse situations in terms of what affords reconciliatory practices, importantly including conversation. Recall that Humberto Maturana mentions "spatial confinement" and "whatever keeps the organisms together" when he writes of the struggle to establish the kind of structural coupling that undergirds communicative interaction. As noted above, Maturana is radical (attentive to the roots) about "conversation," describing it as a "turning around together," a process of coming to orient to another, and maintaining that this orientation is in fact the creative work that precedes communication. ${ }^{73}$

What does it take to privilege and practice "turning around together"? This is at once an existential, ethical, and enactive question, because answering it requires holding together-and-in-tension first, second, and third-personal interactional perspectives. While participatory sense-making is often associated with second-personal approaches to mental phenomena, this is not the full picture. The first-person perspective, even if partially hijacked, never dissolves completely. Participants are not (just) pendulums entrained in an interaction's emergent swing. Moreover, as is implicit in both Buber and Strawson, humans have the third person perspective at their perpetual disposal. While articulating the full story of how an ethically normative and ethically guided cognitive science would study these three perspectives in concrete cases of their entanglement is beyond the scope of the present paper, we build our positive suggestions for improving interracial dialogue in pursuit of this theoretical

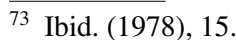


goal. ${ }^{74}$ Reconciliation is a place. What ought to be done in and for this location?

\subsection{Language}

In regards to language, in the place of reconciliation linguistic bodies become self-conscious of their own becoming. ${ }^{75}$ Inhabiting reconciliation involves aiming at interpretation and introspection that is in both cases interruptive. In receiving others' languaging and in attending to my own, I ought to embrace the twin transformations of the enactive ethical account, realizing that there is no such thing as a wholly original or ownable speech act. What would it be like to feel my way towards a partial responsibility for the interaction dynamic, the community norms, and the impersonal linguistic history that infuses my interlocutor's utterances?

A shift from individual to interactional, in-between accountability admits the citational quality of speech: the circulation of signifiers, the unintentionality of repetition, the contagion of catchy or just proximate phrasings. ${ }^{76}$ Various philosophers understand that speech is citational (Derrida, Butler, e.g.); by extension, to the extent that we form ourselves through our utterances, the self is citational. This is the always ethical paradox that linguistic bodies navigate qua linguistic bodies: the utterances I shape with mouth, voice, hands, texts, tweets, and thoughts might be deeply personal or surprisingly alien, or both. And while I'm working to sort that out, the fact remains that to speak, to utter, is to intervene in the world, in the sense-making one does with another, and in the utterance frames and flows by which one builds and maintains oneself. $^{77}$

Furthermore, given that the self is a self-directed flow and set of frames of utterances as suggested by linguistic bodies theory, it becomes evidently unfair to interpret a speech actor (or author) on the basis of a single fragment, soundbyte, or performance. Nonetheless, a key point in participatory sense-making's definition of social interaction is an irreducible element of autonomy and agency for every

\footnotetext{
74 And this goal may be very close to Bejamin's notion of thirdness, which we refer to throughout this text. Thirdness is inherently rhythmic, a meta-pattern of coordination over breakdowns, built on the possibility of repair (Ibid. 2018, 6). This means thirdness is not "an action-reaction pattern" (Ibid. 5). The "open-ended movement of cocreated Thirds" are "distinct from" "the overly tight coordination of doer and done to patterns of reactivity" (Ibid.). We find it illuminating that she explicitly contrasts "opening to the not yet known" with pathological and forced "reactivity" (Ibid.).

75 Di Paolo and De Jaegher, this issue.

76 Fusaroli et al. (2012)

77 Ibid. Di Paolo et al., 314.
}

participant. This unerasable partial agency is why ethical action remains both possible and crucial in every moment. "Linguistic agency is ethical agency precisely because of the ambiguities that coemerge with linguistic powers of critical reflection and self-control." 78 If an agent is to be accountable, somehow both their singular history of navigating utterances and their interactional histories of navigating interpersonal dynamics and relationships must be counted: “... for a more complete enactivist picture we need to combine this domain of inter-individual dynamic presence with the past social conditions which have brought those individuals to this presence."79

Rather than a near-infinitely complex tally system (one thinks of the protracted 'character' cases in the Kavanaugh confirmation hearings), a better practice might be to hold each other accountable as participants through an intentional effort of critical introspection in interaction, one that hones awareness of now past conditioning shows up in present interpretations. A corollary claim would be that a history of social carelessness in interactions, wherein one continually shirks responsibility to co-tend to interactional dynamics, is a moral failure; the same of course would be said in cases of outright domination or willful destruction perpetrated through manipulation and abuse of interactional dynamics (e.g. Donald Trump). In such cases a community would have to do more pointed work in bringing such an individual into a practice of critical participation. Anti-social personalities present an undeniably difficult case. The aim of our interventions is to make visible the myths, projections, associations, and reactions with which one may be unknowingly interacting, to better reach the other in their actual, concrete co-presence that in turn shapes the interaction. An interactional consequence may indeed be new possibilities for doing better which in turn foster changes in attitude.

Participants who practice introspecting about interactions may become more present and responsive to the kaleidoscope of converging first, second, and third-personal perspectives that are all clamoring for attention during an encounter. People have thoughts, feelings, motivations of which they are varyingly and perhaps only vaguely aware during an interaction that nonetheless inform/shape the interaction. These are fast and complex engagements, what Benjamin describes as "the confusing traffic of two-way streets." 80 The normative practice lies in embracing this chaos, allowing critical self-observations to add another layer to the complexity.

\footnotetext{
78 Ibid. 312.

${ }^{79}$ Ibid. Torrance \& Froese (2011), 48.

${ }^{80}$ Ibid. (2018), 22.
} 
Relatedly, we advocate a methodological leaning in to the anxiety about introspection that has plagued psychology from the get-go. Yes, introspecting will change the phenomenon in question; it will alter the interaction dynamics. But we are in fact looking for transformation. We are, following the idea of friction in psychologist Jennifer Eberhardt's work on disrupting racial bias in institutional interactions, seeking to interrupt each other in shared habits of acting as though we are each islands of agency, always quicker to evaluate the other person with whom we are interacting, or to blame ourselves, rather than training our moral sights on the dynamic of which we are part. ${ }^{81}$ Therefore we are also saying, pace Strawson, let us embrace the unnaturalness of becoming more aware of how our affective and attitudinal responses evaluate others. It is okay to take a third-personal stance on our second-personal engagements and first-personal experiences; we will not stop having them as a result, but we may start to have them differently, mindfully, which insofar as it enables critical participation is a good thing.

The goal is interrupting too-neat entrainments of doer and done to that nourish a positive feedback loop in which other-objectifying relations maintain themselves over and against the wills of the individuals involved. Is this deliberate stance possible on a participatory sense-making view? We think so. Participatory sense-making isn't always or even usually a stand-off. How you and I will make sense together here and now cannot be known in advance, and the meaning collectively made is never finished, allowing for a full spectrum of interpretive shades and tones, problems as well as possibilities. Colombetti and Torrance's deployment of participatory sense-making clearly stakes out a phenomenological experience close to Benjamin's description of thirdness. ${ }^{82}$ Similarly, Di Paolo et al. show that a dialectical unfolding of the primordial tension can productively generate shared forms of sense-making, knowing, and relating. ${ }^{83}$ This closely mirrors Benjamin's description of thirdness when she writes, "I have attempted to elaborate the Third as a position that itself develops, from the very basic interactive patterns-rhythmicity-into more complex, symbolically mediated forms of shared reflection, dialogue and negotiation of difference." ${ }^{\prime 4}$ Simply put, languaging together is a matter of becoming, for individuals, interactional units, and embedding institutions alike. Becoming is not necessarily for the better, but we believe that at least being aware of this perpetual dynamism as such can be helpful in developing, over time, and together, sensitivity to multiplicity and complexity. That is the enactive ought. Not to control, close, or

\footnotetext{
$\overline{81 \text { Eberhardt }}$ (2020)

82 Benjamin (2018)

83 Di Paolo et al. (2018)

84 Ibid. (2018), 8.
}

weaponize the dynamics in play, but to transform together towards co-regulating them differently. Being collectively conscious about our vulnerabilities and powers as linguistic bodies together-and being honest about the impersonal as well as personal ways language works - could be a part of what the project that Maiese and Hanna stake out with their "enactive-transformative principle": "we can significantly change our own and other people's essentially embodied minds, and in turn, their lives, whether for worse or better, by means of changing the social institutions we and they inhabit." 85

The primordial tension of participatory sense-making happens as agents resist the interaction dynamic that emerges from their acts in the shared material space of an encounter. We are suggesting not that this tension could be dissipated, but that it might be harnessed. Call-out culture reveals the capability for acquiring fine sensitivities to offense; participants could hone sensitivities instead to situations, places, phrases, felt physical resonances or dissonances that steer our languaging towards or away from harm. Such sensitivities would never be final and would have to stay awake, since we are together billions of different bodies, and what will be harmful is not a straightforward prediction. We imagine this interruptive introspection training would first need to be done after the fact, perhaps in writing (or other kinds of post-hoc conversational analysis). ${ }^{86}$ We plan to explore this through qualitative research in which participants watch video recordings of an interaction in which they participated, re-experiencing the first-person perspective via cues visible from a third-person stance (as for example in the PRISMA method of embodying social interaction research or using a version of descriptive experience sampling) ${ }^{87}$ Work needs to be done to develop and test interruptive introspective strategies. ${ }^{88}$

While experimentation aids in crafting interventions that would in turn engender social reforms, these reforms of course happen 'in the wild'. The recent decision by Twitter to permanently ban ex-president Donald Trump from its platform shows the frighteningly large scope of private corporate power over public life, but also affirms the harm and havoc that social media echo chambers wreak. At the same time, a recent personal example shows how social

\footnotetext{
$\overline{85}$ Maiese and Hanna (2019), 10.

${ }^{86}$ We take this to be at least part of the motivation behind Kendi's Be Antiracist workbook (Kendi, Ibram X. 2020. Be Antiracist: A Journal for Awareness, Reflection, and Action. First edition. New York: One World.).

87 De Jaegher et al., 2019;

${ }^{88}$ Froese, Gould, and Barrett 2011 make a similar plea though not in an applied ethics context.
} 
media can bring stranger-neighbors together, affording colaboring with people who are different from one but in one's community.

\subsection{Labor}

A month before the recent U.S. presidential election, we sold a washer/dryer set to an unknown community member via a local used goods exchange app. I (George) went at night to meet someone who over the phone sounded like a middleaged white man with an identifiably provincial drawl. Elena expressed concerned for my safety-it seemed like the set up for an absurd movie, where a MENA man is murdered by a white Trump voter who claimed to be fighting terrorism.

I cannot say what the buyer thought was going to happen, but when we met it was clear that I was not at all what he expected. I was wearing a mask, he was not. This alone is a potential two-way offense: I, wearing a mask, am offended that the stranger whom I am meeting during a pandemic is not. He, not wearing a mask, could either be offended by my presumed liberal sensibilities or by a racially associated fear of robbery/attack (or both). The mask difference was already enough to derail the interaction-but what could I do? I needed this man to help me and I was in turn helping him.

Our initial engagements were awkward, but I did my best to moderate the situation by asking him questions about himself. These questions landed with mixed results until it became clear that the washer/dryer set, which was in a basement, needed to be lugged up a flight of stairs that was only an inch wider than the objects themselves. While trying to detach the dryer unit from the top of the washer, the man asked what I did for a living and I said that I was a professor. He was stunned, but instead of saying something terrible (which I now realize I was fully expecting), he asked what I teach. I said I teach political theory and ethics, and this afforded a pivot point in the interaction, which occurred along with our attempt to literally pivot the unit over to the outside staircase: He asked what I thought of Trump and Biden. I expressed general disdain for macropolitical actors and said that too many people are dying for the show to go on. He said he was a Trump voter. I said, "There is a lot of that around here." Now, this is where the conversation is supposed to abruptly end or lead to violence. But, he went on, explaining that Biden was going to shut down the economy again, and since he was self-employed that meant that he was concerned for the wellbeing of his family.

We were now carrying one of the machines up a narrow concrete staircase in the cold. After getting the first unit up the steps, he asked more questions about my work and I told him that I spent a decent amount of time studying conflict and post-conflict reconciliation. I shared that what we are living through with U.S. politics looks a lot like the spaces I study before complete civil war breaks out, and I emphasized this as my greatest worry. He agreed with me and conceded that most anything would be preferable to war. Our conversation went on in various directions, but slowed as we became more exhausted by the literal weight of our task. When we had finally gotten both units up the steps, he paid me and said thank you. I thanked him and thought we were going to part ways. Before he reached his truck, he turned back and invited me to join his family at their church. He said that they have a regular meal there and my family and I would be welcome. I said thank you again and wished him well.

While driving home I thought about a text that I regularly teach: Enrique Dussel's Ethics and Community, which is a difficult read for many because of its reliance on Catholic thought and biblical text to make liberatory claims. ${ }^{89}$ Yet it is exactly Dussel's redeployment and critical engagement with a broadly known framework, for radical ends, that makes the text so interesting. The starting point for Dussel is the face-to-face encounter, praxis, which is an interesting inversion of the way that praxis is typically understood, i.e., as theory put to practice; instead, Dussel, following the tradition of Ludwig Feuerbach and Emmanuel Levinas, claims that praxis, the face-to-face encounter, ought to be primary, while theory, thought, or meaning more generally ought to be transformed from the real material interaction.

In this encounter with the man buying the washer/dryer set, initial projections were destabilized, on both sides, through bodily coordinations (physical, linguistic) in space and time co-afforded by common labor towards a common end. I may not have immediately changed his mind about Trump, or about MENA people more generally, but in this moment we both became for each other something more than our assumptions. It would be too superficial to say that we were both just in it for the transaction at hand; this is a case of the weight of a present social and material situation conscripting two people into a meaning-making encounter that neither individual desired or planned, one that pushed back against the projections and myths. This is the sort of possibility that we have to latch onto and consciously cultivate, together, if opposing parties are to stop seeing each other as enemies and start seeing truly different, concrete, vulnerable, and valuable bodies open to engaging and enacting a shared world. However, the possible 'we' that could meaningfully emerge requires that the burden of care in interactions be shared by all involved parties. In other words, those who operate from a position of power and privilege need to start doing this sort of work, exemplified through our reading of Rankine, if there is any hope of an anti-racist or peaceful future. The oppressed will only extend the olive branch for so long before James Baldwin's prophetic fire turns possibility to ash. Of course, these sorts of entrenched norms will

\footnotetext{
$\overline{89}$ Dussel (1988).
} 
not change overnight-especially for those who benefit from asymmetrical relations - which is why we use the language of training and an evaluative framework that considers one's citational existence over time.

\section{Conclusion}

In analyzing an illustration of how, following Heidegger, the ontological condition of people in everyday situations is that of thrownness, computer scientists Winograd and Flores make five observations, addressed to a singular individual. In any given situation of significant social interaction, (1) you cannot avoid acting (2) you cannot step back and reflect on your actions (3) the effects of actions cannot be predicted (4) you do not have a stable representation of the situation (4) every representation (in the sense of post-mortem re-presenting, e.g. Rankine's poetic prose) is an interpretation and (5) language is action. ${ }^{90}$ As we work to develop ameliorative ethical possibilities out of enactive concepts, we must keep these significant hermeneutic parameters in mind. This is the mess in which we engage each other, continually. Our suggestions, and intended research into introspective and interactive interventions, are offered not in the spirit of predictand-control, mechanistic improvements (Radiohead's robot voice pronouncing "thinner, happier, more productive"). Nor do we want to encourage blind engagement for its own sake according to a surveillance-capitalist logic of "more is always better." For participation to achieve critical ends it must be conducted on its own terms, which means on the terms of the particular participants in that particular moment, unfinished and in becoming, and in important ways, somewhat beyond their own control. How can one take all this into account and still be speaking of ethical action and moral responsibility?

As we have argued, we think that enactive theory and the normative implications of participatory sense-making as elaborated in the account of linguistic bodies are helpful precisely because these tools do not come from the traditional Western ethics tool-box. They are, as Di Paolo and De Jaegher argue, more primordial than the inherited tradition of methodological and metaphysical individualism, of praise-and-blame, doer-done-to practices of judgment. ${ }^{91}$ What this can mean on the ground for real problems communities face remains open and necessarily open-ended. We won't know until we try.

In our analysis of location, language, and labor as sites of interactional intervention, we have invoked the notion of training over time and the importance of communities. A

\footnotetext{
${ }^{90}$ Winograd and Flores (1986), 34-35.

91 See, this issue.
}

possible avenue for experimental application of our ideas may be found in workplace anti-racism trainings, which vary widely and some of which have come under scrutiny for possible rigidity and class-insensitivity. ${ }^{92}$ Indeed, Dussel emphasizes that institutional efforts to liberate can become themselves modes of domination, fetishizing and thus reifying themselves as if they should not (or cannot) change. ${ }^{93}$

There will always be work to do. What we hope to have achieved for the moment is primarily a demonstration that enactive theory reveals concrete contemporary ethical and political problems in new light. Enactive cognitive science increasingly points to process and becoming, the dissolution of self, the decentering tendencies of linguistic selfhood, and the entanglement of perspectives. Our ethics must respond to reality as we know it. The shared life enactive language speaks clarifies existing positions and efforts, reorienting concrete struggle against racism and white supremacy.

Acknowledgements The authors wish to thank Megan Burke, Hanne De Jaegher, Ezequiel Di Paolo, Jose Mendoza, and Maceo Whatley for comments on an earlier version of the paper. Thanks also to comments received during the anonymous review process.

Open Access This article is licensed under a Creative Commons Attribution 4.0 International License, which permits use, sharing, adaptation, distribution and reproduction in any medium or format, as long as you give appropriate credit to the original author(s) and the source, provide a link to the Creative Commons licence, and indicate if changes were made. The images or other third party material in this article are included in the article's Creative Commons licence, unless indicated otherwise in a credit line to the material. If material is not included in the article's Creative Commons licence and your intended use is not permitted by statutory regulation or exceeds the permitted use, you will need to obtain permission directly from the copyright holder. To view a copy of this licence, visit http://creativecommons.org/licenses/by/4.0/.

\section{References}

Backström J, Nykänen H, Toivakainen N, Wallgren T (2019) Moral Foundations of Philosophy of Mind. Palgrave Macmillan

Barrett NF, García-Valdecasas M, Sánchez-Cañizares J (2018) 'I Can' vs. 'I Want': what's missing from gallagher's picture of nonreductive cognitive science. Australas Philosophical Review 2(2):209-213. https://doi.org/10.1080/24740500.2018.1552099

Benjamin, Jessica. 2018. Beyond Doer and Done to: Recognition Theory, Intersubjectivity and the Third. 1 online resource (276 pages) vols. London: Taylor and Francis. http://search.ebscohost. com $/ \operatorname{login}$. aspx ?direct $=$ true $\&$ scope $=$ site $\& d b=$ nlebk $\& d b=$ nlabk $\& \mathrm{AN}=1552081$.

Bordo S (1999) The Male Body: A New Look at Men in Public and in Private, 1st edn. Farrar, Straus and Giroux, New York

Braithwaite J (1989) Crime, Shame, and Reintegration. University Press, Cambridge

\footnotetext{
$\overline{92}$ Powell, M. "Inside a Battle Over Race, Class and Power at Smith College.” New York Times. March 3, 2021.

${ }^{93}$ Dussel (1988), specifically 75-77 or his general discussion of the ethical becoming the prevailing moral order and thus creating a different subjugated class.
} 
Braithwaite J . 2000. "REINTEGRATIVE SHAMING.” http://johnb raithwaite.com/wp-content/uploads/2016/05/2000_ReintegrativeShaming.pdf.

Brancazio N (2020) Being perceived and being "seen": interpersonal affordances, agency, and selfhood. Front Psychol 11:1750. https:// doi.org/10.3389/fpsyg.2020.01750

Buber M (1996) I and Thou. 1st, Touchstone. Touchstone, New York

Burke M (2019) When Time Warps: The Lived Experience of Gender, Race, and Sexual Violence. University of Minnesota Press, Minneapolis. https://doi.org/10.5749/j.ctvpwhd7z

Chemero, Anthony. 2009. Radical Embodied Cognitive Science. A Bradford Book. Cambridge: MIT Press, The MIT Press.

Colombetti G, Torrance S (2009) Emotion and ethics: an inter-(En) active approach. Phenomenol Cogn Sci 8(4):505-526. https:// doi.org/10.1007/s11097-009-9137-3

Cooper BC (2018) Eloquent Rage: A Black Feminist Discovers Her Superpower, 1st edn. St. Martin's Press, New York

Cuffari EC, Di Paolo E, De Jaegher H (2015) From participatory sense-making to language: there and back again. Phenomenol Cogn Sci 14(4):1089-1125. https://doi.org/10.1007/ s11097-014-9404-9

Dierckxsens G (2020) Enactive cognition and the other: Enactivism and levinas meet halfway. J French and Francophone Philos 28(1):100-120. https://doi.org/10.5195/jffp.2020.930

Dussel, Enrique D. 1988. Ethics and community. Liberation and theology series. Maryknoll, NY: Orbis Books.

Eberhardt, Jennifer L. 2020 Biased: Uncovering the hidden prejudice that shapes what we see, think, and do. Penguin Books

Fourlas GN (2015a) No future without transition: a critique of liberal peace. Intern J Transit Justice 9(1):109-126. https://doi.org/10. 1093/ijtj/iju029

Fourlas GN (2015b) A politics of reconciliation: trust, legitimacy, and the need for truth commissions. J Peace \& Justice Studies 25(2):29-55. https://doi.org/10.5840/peacejustice201525213

Frankowski, Alfred. 2012. "The Cassandra Complex: On Violence, Racism, and Mourning." https://scholarsbank.uoregon.edu/ xmlui/handle/1794/12463.

Fusaroli R, Bahrami B, Olsen K, Roepstorff A, Rees G, Frith C, Tylén K (2012) Coming to terms: quantifying the benefits of linguistic coordination. Psychol Sci 23(8):931-939

van Grunsven JB (2018) Enactivism, second-person engagement and personal responsibility. Phenomenol Cogn Sci 17(1):131-156. https://doi.org/10.1007/s11097-017-9500-8

Helm, Bennett. 2013. "Trust as a Reactive Attitude." In Oxford Studies in Agency and Responsibility, edited by David Shoemaker and Neal A. Tognazzini, 187-215. Oxford University Press.

Hutchinson, Phil. 2019. "The Missing 'E': Radical Embodied Cognitive Science, Ecological Psychology and the Place of Ethics in Our Responsiveness to the Lifeworld." In Moral Foundations of Philosophy of Mind, edited by Joel Backström, Hannes Nykänen, Niklas Toivakainen, and Thomas Wallgren, 103-27. Cham: Springer International Publishing. https://doi.org/10. 1007/978-3-030-18492-6_4.

Jaegher De, Hanne Barbara Pieper, Clénin Daniel, Fuchs Thomas (2017) Grasping intersubjectivity: an invitation to embody social interaction research. Phenomenol Cogn Sci 16(3):491-523

Jaegher De, Hanne, and Ezequiel Di Paolo. (2007) Participatory sense-making: an enactive approach to social cognition. Phenomenol Cogn Sci 6(4):485-507. https://doi.org/10.1007/ s11097-007-9076-9

De Jaegher H (2018) The intersubjective turn. In: Newen A, De Bruin L, Gallagher S (eds) The Oxford Handbook of 4E Cognition. Oxford University Press, pp 453-468

Johnson M (2014) Morality for Humans: Ethical Understanding from the Perspective of Cognitive Science. The University of Chicago Press, Chicago
Johnson, T. 2020. "When black people are in pain, white people just join book clubs." The Washington Post. June 11 2020. https:// www.washingtonpost.com/outlook/white-antiracist-allyshipbook-clubs/2020/06/11/9edcc766-abf5-11ea-94d2-d7bc43b26b f9_story.html

Kendi IX (2019) How to Be an Antiracist. One World, New York

Kendi IX (2020) Be Antiracist: A Journal for Awareness, Reflection, and Action, 1st edn. One World, New York

Lederach JP (1997) Building Peace: Sustainable Reconciliation in Divided Societies. United States Institute of Peace Press, Washington, DC

Lorde A (2007) Sister Outsider: Essays and Speeches. Ten Speed Press, Berkeley, Calif.

Loretta Ross. 2019. "Call-Out Culture Is Toxic: Op-Ed." The New York Times, 2019, Late Edition (East Coast) edition.

Maiese M, Hanna R (2019) The Mind-Body Politic. Palgrave Macmillan

Maturana, Humberto R. 1978 "Biology of language: The epistemology of reality $25-82$

Mills C (1997) The Racial Contract. Cornell University Press, Ithaca. https://doi.org/10.7591/j.ctt5hh1wj

Métais F, Villalobos M (2020) Embodied ethics: levinas' gift for enactivism. Phenomenol Cogn Sci. https://doi.org/10.1007/ s11097-020-09692-0

Oluo I (2020) Mediocre: The Dangerous Legacy of White Male America, 1st edn. Seal Press, New York

Oluo, Ijeoma. 2018. So You Want to Talk about Race. First edition. New York, NY: Seal Press. https://books.google.com/books? isbn $=1580056784$.

Paolo Di, Ezequiel A (2018) Linguistic Bodies: The Continuity between Life and Language. The MIT Press, Cambridge, Massachusetts

Pateman C, Mills CW (2007) Contract and Domination. Polity, Cambridge

Quijano A (2007) Coloniality and modernity/rationality. Cultural Studies (london, England) 21(2-3):168-178. https://doi.org/10. 1080/09502380601164353

Raja V, Chemero A (2020) In favor of impropriety. Constructivist Foundations 15(3):213-216

Rankine C (2020) Just Us: An American Conversation. Graywolf Press, Minneapolis, Minnesota

Reiman JH (2010) The Rich Get Richer and the Poor Get Prison: A Reader. Allyn \& Bacon, Boston, MA

Sidanius J, Pratto F (1999) Social Dominance: An Intergroup Theory of Social Hierarchy and Oppression. University Press, Cambridge

Solnit, R. 2014. Men explain things to me. Haymarket Books.

Steiner P, Stewart J (2009) From autonomy to heteronomy (and back): the enaction of social life. Phenomenol Cogn Sci 8(4):527-550. https://doi.org/10.1007/s11097-009-9139-1

Sylvia Wynter. 2003. "Unsettling the Coloniality of Being/Power/ Truth/Freedom: Towards the Human, After Man, Its Overrepresentation-An Argument." CR (East Lansing, Mich.) 3 (3): 257-337. https://doi.org/10.1353/ncr.2004.0015.

Tempels P (1969) Bantu philosophy. Présence africaine, Paris

Torrance S, Froese T (2011) 'An inter-enactive approach to agency: participatory sense-making, dynamics, and sociality'. Humana. Mente 15 (2011): 21-53. Humana Mente, 15:21-53

Urban P (2014) Toward an expansion of an enactive ethics with the help of care ethics. Front Psychol 5:1354-1354. https://doi.org/ 10.3389/fpsyg.2014.01354

Urban P (2015) Enacting Care. Ethics and Social Welfare 9(2):216222. https://doi.org/10.1080/17496535.2015.1022356

Varela, Francisco J. 1999. Ethical Know-How: Action, Wisdom, and Cognition. Writing Science. Stanford, Calif: Stanford University Press. 
Wilkerson, Isabel. 2020. Caste: The Origins of Our Discontents. 1 online resource (xvii, 477 pages) vols. New York: Random House. https://www.overdrive.com/search?q=E995569A-F33F41CC-8BAA-F33F46D85098.

Winograd, Terry, and Fernando Flores 1986. Understanding Computers and Cognition: A New Foundation for Design. Language and Being. Norwood, NJ: Ablex Publishing Corporation.
Yancy G (2018) Backlash: What Happens When We Talk Honestly about Racism in America. Rowman \& Littlefield, Lanham

Publisher's Note Springer Nature remains neutral with regard to jurisdictional claims in published maps and institutional affiliations. 